REVISTA DE DERECHO UNED, NÚM. 10, 2012

\title{
ALGUNAS CLAVES SOBRE EL VALOR JURÍDICO DEL SILENCIO
}

\author{
José Antonio Martínez Vela \\ Universidad de Castilla-La Mancha
}

Resumen: A partir de la Pandectística y su construcción del Negocio Jurídico, una de las cuestiones que mayor interés ha planteado en la doctrina privatística es la referente a si el Silencio puede constituir o no la base de una auténtica declaración de voluntad, o, en su caso, cuál es el fundamento que se encuentra tras aquellos preceptos que imputan determinados efectos jurídicos a la conducta pasiva de un sujeto, siendo el ámbito de los contratos aquél donde el tema se plantea con mayor frecuencia.

Partiendo de un estudio de cómo es concebido en el ámbito de las ciencias sociales el fenómeno del silencio, se analiza a continuación cómo fue percibida esta situación en la esfera del Derecho Romano, procediendo más adelante a analizar la situación en Derecho Español, con especial referencia a la legislación foral navarra, y en Derecho Comparado, donde cabe destacar cómo es precisamente en las legislaciones civiles más recientes donde este problema aparece contemplado de modo explícito.

Abstract: From the Pandectism and its construction of the Legal Act, one of the most interesting question arised in the romanistic doctrine is if the Silence can be the ground of a real declaration of will, or which are the foundations behind that norms where to a man's passive behavior is connected some juridical effects; this situation is precisely really important in Contract Law.

Our point of depart is how the problem of the silence is conceived in the social sciences; after that, we are going to analyze how this si- 
tuation has been noticed in the Roman Law, in the spanish private Law -with special reference to the Navarra's Foral Law- and in comparative Law.

Palabras Clave: Silencio - Contratos - Derecho Romano - D. 50.17.142 - Ley 20 Compilación Foral de Navarra - Derecho Comparado.

Key words: Silence - Contracts - Roman Law - D. 50.17.142 Navarra's Foral Law 20 - Comparative Law.

Sumario: I.-Introducción. II.-Breve Caracterización del Fenómeno del Silencio. III.-El Valor del Silencio en Derecho Romano: Algunas Claves en Derecho Contractual. IV.-La Caracterización del Silencio en el Derecho Civil Español. V.-Visiones del Silencio en Derecho Civil Comparado.

I.- El punto de partida de este trabajo se encuentra en una investigación previa llevada a cabo con relación a la institución de la tácita reconducción en Derecho Romano ${ }^{1}$, donde profundizamos en un debate surgido en el mundo jurídico del siglo XIX, en concreto, dentro de la Pandectística alemana ${ }^{2}$, respecto al concepto de «Negocio Jurídico», pudiéndose afirmar con cierta rotundidad tanto que la mera voluntad interna es inaferrable e incognoscible, pues pertenece únicamente al foro de la conciencia individual ${ }^{3}$, como que -tal y como ya se puso de relieve por el Prof. SAVIGNY- la voluntad misma, como hecho interno, no podía darse a conocer sino valiéndose de la

1 José Antonio MARTÍNEZ VELA, La relocatio tacita, ¿puede el silencio constituir una auténtica declaración de voluntad?, Tesis Doctoral, Albacete, 2008.

2 Ver Antonio FERNÁNDEZ DE BUJÁN, Derecho Público Romano. Recepción, Jurisdicción y Arbitraje ${ }^{11}$, Madrid, 2008, págs. 272-274.

${ }^{3}$ Esta idea ya fue defendida tanto por el Prof. Clemente DE DIEGO, El Silencio en el Derecho, Madrid, 1925, pág. 52: «[...]la expresión o manifestación de voluntad es necesaria en el acto jurídico, porque los estados internos del alma, por sí, no pueden tener valor para el Derecho; sólo traídos hacia fuera y manifestados, dados a conocer a los demás, es como adquieren transcendencia social y estado jurídico [...]»; como por el Prof. Alfred RIEG, Le rôle de la volonté dans l'acte juridique en droit civil français et allemand, Paris, 1961, pág. 37, quien afirmaba que: «si la volonté du for interne doit exister, cela est néanmoins insuffisant pour lui permettre de jouer un rôle sur le plan juridique. Encore faut-il qu'elle soit extériorisée, manifestée, ou, pour employer le mot traditionnel, déclarée. Il est évident qu'une volonté demeurée dans le for intérieur ne constitue qu'une simple réalité psychologique sans prise sur le domaine du Droit. On peut donc dire, tout en précisant ultérieurement les différents termes de la formule employée, que «la déclaration de volonté est... le procédé par lequel la volonté interne parvient a la connaissance des tiers» $[\ldots] »$. 
mediación de un signo sensible, exterior ${ }^{4}$, siendo innegable como ha señalado el Prof. Antonio FERNÁNDEZ DE BUJÁN que «la voluntad de los intervinientes en el negocio debe expresarse para producir efectos jurídicos $»^{5}$, pues como ya indicó el Prof. Vittorio SCIALOJA «l'elemento fondamentale e la nota comune di ogni negozio giuridico è l'estrinsecazione della volontà ${ }^{6}$, o, como han afirmado los Profs. J. ARIAS RAMOS y J. A. ARIAS BONET, no puede desconocerse que «la voluntad que no se exterioriza carece de eficacia jurídica» ${ }^{7}$. Es decir, aun cuando en base a la Autonomía Privada se considere que el nervio del negocio jurídico no es otro sino la "Voluntad» ${ }^{8}$-así, en palabras de Santo TOMÁS DE AQUINO, «quod radix libertatis est voluntas ${ }^{9}-$-, lo cierto es que en tanto en cuanto dicha voluntad no se proyecta hacia el exterior no es conocida, y por tanto no puede recibir ningún tipo de eficacia jurídica ${ }^{10}$ : la voluntad meramente interna

${ }^{4}$ Friedrich Carl von SAVIGNY, Sistema del Derecho Romano Actual, Granada, 2005, § CXXXI, pág. 460.

5 Antonio FERNÁNDEZ DE BUJÁN, Derecho Privado Romano ${ }^{3}$, Madrid, 2010, pág. 318.

6 Vittorio SCIALOJA, Negozi Giuridici. Corso di Diritto Romano: 1892-1893, Roma, 1933, pág. 29. Esta misma idea ha sido expresada por el Prof. A. VON TÜHR, Tratado de las Obligaciones, Madrid, 1934, pág. 107.

7 J. ARIAS RAMOS-J.A. ARIAS BONET, Derecho Romano. Vol. $I^{18}$, Madrid, 1986, pág. 128.

8 Ver Juan IGLESIAS, Derecho Romano ${ }^{12}$, Barcelona, 1999, pág. 107. En idéntico sentido se manifiesta el Prof. Federico DE CASTRO Y BRAVO, El Negocio Jurídico, Madrid, 1985, págs. 56-57.

Respecto al vivo debate que a partir del siglo XIX surgió con relación a la prevalencia de la Voluntad «real» sobre la Voluntad «declarada», no es éste el lugar para un análisis detenido y detallado respecto a las diversas teorías que se han planteado, desde las extremos de la «Teoría de la Voluntad» y de la «Teoría de la Declaración», pasando por las intermedias de la «Teoría de la Confianza» o de la «Teoría de la Responsabilidad»; sobre esta cuestión, pueden también consultarse: Alberto VIGHI, Considerazioni sulla dichiarazione tacita di volontà, Camerino, 1899, págs. 12-34; Giovanni PACCHIONI, Corso di Diritto Romano. Vol. $I^{2}$, Turín, 1920, págs. 213-217; Manuel ALBALADEJO, El Negocio Jurídico, Barcelona, 1958, págs. 151-165; Giuseppe STOLFI, Teoria del Negocio Jurídico, Madrid, 1959, págs. 131-134; Federico DE CASTRO Y BRAVO, op. cit., págs. 58-60; Paulo CARDOSO CORREIA DA MOTA PINTO, Declaração Tácita e Comportamento Concludente no negócio jurídico, Coimbra, 1995, págs. 18-52; Werner FLUME, El Negocio Jurídico, Madrid, 1998, págs. 83-89; Luis DÍEZ PICAZO, Fundamentos del Derecho Civil Patrimonial. Tomo I ${ }^{5}$, Madrid, 1996, págs. 152-156; Emilio BETTI, Teoria General del Negocio Jurídico, Granada, 2000, págs. 341-402.

9 SANTO TOMÁS DE AQUINO, S. Th. 1, 2ae, q. 17, 1, ad 2.

10 A este respecto, ya indicó el Prof. Alfred RIEG, Le Rôle de la volonté dans l'acte juridique en droit civil français et allemand, Paris, 1961, pág. 15, que: «l'acte juridique étant défini comme une manifestation de volonté destinée à créer des effets de droit, l'existence même de cette volonté constitue la condition de base sans laquelle aucun acte juridique ne saurait naître [...]». 
nada puede producir ${ }^{11}$, afirmaba el Prof. LARENZ. Es decir, tal y como señaló el Prof. Biondo BIONDI «La volontà in tanto puó costituire la base di un negozio in quanto sia manifestata. Manifestare la volontà significa estrinsecarla in qualche atto esterno, in guisa che possa essere percepita da altrui. Una volontà inespressa od un semplice proponimento non ha effetti» ${ }^{12}$, pues como ya afirmaba el jurista romano $\mathrm{Celso}^{13}$ :

«nam etsi prior atque potentior est quam vox mens dicentis, tamen nemo sine voce dixisse existimatur» ${ }^{14}$.

Ahora bien, ¿cuáles son las formas o medios a través de los cuales dicha voluntad puede ser exteriorizada, puede ser dada a conocer al mundo exterior para así adquirir virtualidad jurídica? Dichas formas son muy variadas, pues siguiendo al Prof. Natalino IRTI «l'altrui pensiero ci si rivela per tramite molteplici: visivi (linguaggio scritto e linguaggio mimico), auditivi (linguaggio parlato, e -più di rado- silenziosi (linguaggio muto)» ${ }^{15}$, precisando todavía más el Prof. STOLFI quien afirma que «para manifestar su voluntad la parte ha de hacer comprender aquello que efectivamente quiere: con tal finalidad puede utilizar todos los medios adecuados por su naturaleza para ex-

11 Ver: Karl LARENZ, Derecho Civil. Parte General, Madrid, 1978, pág. 450.

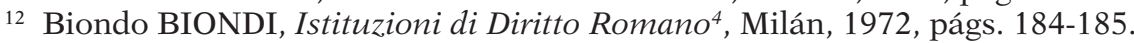

En una línea muy similar se han manifestado, por ejemplo, el Prof. Matteo MARRONE, Istituzioni di Diritto Romano, Palermo, 1989, pág. 162, o el Prof. Adolfo RAVA, Istituzioni di Diritto Privato, Padova, 1938, pág. 118.

${ }^{13}$ P. Iuventius Celsus, Celso hijo, fue uno de los juristas más agudos y brillantes de la escuela proculeyana, desarrollando su actividad en la primera mitad del siglo II d.C., teniendo un importante papel en la vida pública, al alcanzar en dos ocasiones la dignidad de cónsul y formar parte del consilium principis del emperador Adriano. Destacó por su independencia intelectual y su habilidad como polemista. Entre sus obras, destacan los 39 libri digestorum, sus 11 Libri epistolarum o sus 12 Libri Quaestionum.

Ver: Mario BRETONE, Note minime su Celsus Filius, en «Labeo», vol. IX, 1963, págs. 331-345; Herbert HAUSMANINGER, Publius Iuventius Celsus: Persoenlichkeit und juristische Argumentation, en «A.N.R.W.», II.45, 1976, págs. 382-407; Pietro CERAMI, Verba e Voluntas in Celso figlio, en «Studi A. Arena», Palermo, 1979, págs. 3-10; Vincenzo SCARANO USSANI, Empiria e Dogmi. La scuola proculiana fra Nerva e Adriano, Turín, 1989; Herbert HAUSMANINGER, Celsus gegen Proculus, en «Tradition und Fortentwicklung im Recht. Festschrift zum 90. Geburtstag von Ulrich von Lübtow», Berlin, 1990, págs. 53-62; Filippo GALLO, Agere praescriptis verbis e editto alla luce di testimonianze celsine, en «Labeo», vol. XLIV, 1998, págs. 7-25; Alberto BURDESE, Su alcune testimonianze celsine, en «Melanges en l'honneur de Carlo Augusto Cannata», 1999, págs. 3-13.

${ }^{14}$ D. 33.10.7.2 (CELSO, libr. XIX dig.): «porque aunque es anterior y más poderosa que la voz la intención del que habla, sin embargo, no se estima que nadie habló sin voZ».

15 Natalino IRTI, La ripetizione nel negozio giuridico, Milán, 1970, pág. 2. 
teriorizar su interno querer, como de palabra o por escrito, o que en la esfera de los interesados tengan esta función, como, por ej., los simples gestos o, en general, cualquier actitud que según los usos y las circunstancias del caso, induzcan a la certeza de la existencia de una voluntad dada y de cierto contenido ${ }^{16}$, habiéndose manifestado en este mismo sentido el Tribunal Supremo español, según el cual por «Declaración de Voluntad» ha de entenderse como: «aquella manifestación que pueda hacerse a través de diversos medios que van desde el empleo del lenguaje, ya sea verbal, escrito o simplemente mímico, hasta el mero silencio, cuando por la peculiar situación del sujeto deba entenderse, por sí mismo, como una expresión de voluntad ${ }^{17}$, pues como muy acertadamente señala el Prof. Antonio FERNÁNDEZ DE BUJÁN, con relación al Derecho Romano, «si bien, con carácter general, se establece que el silencio no supone declaración de voluntad, en determinados supuestos, se le reconoce este valor, así en la mancipatio, en la in iure cessio, o en los arrendamientos rústicos, al ser considerados como asentimiento» ${ }^{18}$.

II.- Cuando nos referimos al Silencio, tal y como ya señaló el Prof. KURZON, estamos aludiendo a un estado, o más concretamente a la ausencia de un tipo determinado de actividad, esto es, del discurso ${ }^{19}$; así, la primera acepción que se contiene de este término dentro del Diccionario de la Real Academia de la Lengua Española es la de "Abstención de hablar» ${ }^{20}$, mientras que el Diccionario del Uso del Español María Moliner lo define como «circunstancia de no haber ningún sonido en un sitio o en un momento. Circunstancia de no hablar las personas. Circunstancia de no hablar de cierta cosa» ${ }^{21}$. Parece, por tanto, evidente, que el silencio ha de ser entendido como la ausencia de todo discurso, de todo sonido, de todo ruido ${ }^{22}$, siendo ya

${ }^{16}$ Giuseppe STOLFI, Teoría del Negocio Jurídico, Madrid, 1959, págs. 202-203.

17 Sentencia del Tribunal Supremo, de 7 de diciembre de 1966.

18 Antonio FERNÁNDEZ DE BUJÁN, Derecho Privado Romano ${ }^{3}$, Madrid, 2010, pág. 318.

19 Dennis KURZON, Discourse of Silence, Amsterdam, 1997, págs. 1-2. En idéntico sentido se ha manifestado el Prof. R. NERSON, Le Silence (étude de droit civil français), en "Eranion in onorem Georgi S. Marikadis», vol. II, Atenas, 1963, pág. 399.

20 Diccionario de la Real Academia de la Lengua ${ }^{21}$, Madrid, 1998, pág. 1879.

21 Diccionario del Uso del Español María Moliner, ed. abreviada, Madrid, 2000, pág. 1282.

${ }^{22}$ Hemos de advertir, no obstante, que algunos autores en cierto modo vienen a poner en duda esta máxima, pues niegan el carácter absoluto del silencio, siendo un claro representante de esta opinión el Prof. Thomas J. BRUNEAU, Communicative 
apreciado de este modo en el mundo antiguo, como se evidencia por ejemplo del siguiente texto de San Agustín: «Sic et tardum dicimus veloci contrarium: sed tamen qui se omnino non movet, nec tardus dici potest. Sic acutae voci contrariam vocem dicimus gravem, vel canorae asperam: sed si omnem speciem vocis penitus adimas, silentium est ubi vox nulla est: quod tamen silentium, eo ipso quod vox nulla est, tamquam contrarium voci solet opponi. Sic et lucida et obscura tamquam duo contraria dicuntur: habent tamen et obscura aliquid lucis, quo si penitus careant, ita sunt tenebrae lucis absentia, sicut silentium vocis absentia» ${ }^{23}$, mientras que Isidoro de Sevilla afirmaba: «sicut silentium non aliqua res est, sed ubi sonus non est, silentium dicitur» ${ }^{24}$.

Otro hecho constatado e innegable es que el ser humano puede incluso expresarse a través del silencio, pues como afirma HEIDEGGER el ser humano habla; hablamos despiertos y en sueños; hablamos continuamente; hablamos incluso cuando no pronunciamos palabra alguna ${ }^{25}$, siendo -no obstante- la principal dificultad que plantea el silencio descubrir el significado que éste tiene en cada contexto o supuesto en el cual nos encontramos con él ${ }^{26}$; pues, en palabras del Prof. Bode SOWANDE «silence has its own language and must by interpretation be understood as a means of communication ${ }^{27}$, ya que el silencio puede expresar cosas totalmente opuestas como puso de relieve el Prof. E. DAVID: «The complex nature of silence is revealed «inter alia» by its power to convey an impressive range of diametrically opposed messages: e.g., consent/disapprobal; respect/contempt; sympathy/antipathy; intimacy/alienation; politeness/rudeness» ${ }^{28}$; no pudiendo dejarse tampoco de compartir la afir-

Silences: Forms and Functions, en «The Journal of Communication», vol. 23, 1973, pág. 17, afirma: «Silence does not exist in the physical absolute -notions to be contrary are mythical. John Cage said it simply: «There is no such thing as absolute silence, something is always happening that makes a sound» [...]. Absolute silence, then, is imposible: even when not speaking aloud, man carries on a continuous interior monologue».

${ }^{23}$ SAN AGUSTÍN, De natura boni contra Manichaeos Liber Unus 15. Ver también: PLUTARCO, Moralia 947.A

${ }^{24}$ San ISIDORO DE SEVILLA, Etymologiarum XIII.10.12.

${ }^{25}$ Martin HEIDEGGER, De camino al habla 3 , Barcelona, 2002, pág. 9.

26 A este respecto, la Prof. Maria Sara GORETTI, Il Problema Giuridico del Silenzio, Milán, 1982, pág. 15, ya advertía de que «[...]è facile, pur senza inoltrarsi negli spinosi problemi gnoseologici, pensare che l'interpretazione del silenzio non può mai raggiungere quel grado di chiarezza e univocità che hanno la parola, il gesto, o un fatto qualsiasi $[\ldots] »$.

27 Bode SOWANDE, op. cit., pág. 394.

28 E. DAVID, Sparta's Kosmos of Silence, en «Sparta: new perspectives», Londres, 1999, pág. 117. 
mación del Prof. KURZON de que «It is an old adage that silence is meaningful. The central problem of silence in discourse is to discover that meaning ${ }^{29}$.

A esta dificultad de la multiplicidad de significados que pueden atribuirse al silencio, se ha de sumar otra, pues si el silencio hemos de entenderlo como una forma a través de la cual puede ser expresada una determinada opinión o voluntad, ha de tratarse -sin duda- de un medio de comunicación no-verbal. Ahora bien, no podemos desconocer tampoco que en ocasiones -como también ha señalado el Prof. KURZON- «silence may be unintentional; people are sometimes silent without meaning anything specific by their silence» ${ }^{30}$; es decir, en ocasiones el silencio no ha sido voluntario, ha sido no-intencionado ${ }^{31}$, lo cual ha de plantear mayores dificultades a la hora de atribuirle o no algún tipo de valor, pues además suele tratarse de un silencio de naturaleza básicamente psicológica, pues dicha persona que se mantiene en silencio no tiene ningún tipo de control sobre su respuesta a la cuestión que le ha sido planteada, cayendo en el silencio debido a toda una serie de inhibiciones psicológicas.

Así, el Prof. KURZON ${ }^{32}$ procede a enumerar toda una serie de situaciones en las cuales una persona mantiene este tipo de silencio no intencionado, entre las cuales destaca el hecho de que muchos individuos se sienten inhibidos al serles planteadas ciertas cuestiones debido a que dicha inhibición es parte de su modo de ser psicológico:

${ }^{29}$ Dennis KURZON, Discourse of Silence, Amsterdam, 1997, pág. 5.

${ }^{30}$ KURZON, ult. op. cit., pág. 18.

31 Frente a esta diferenciación del Prof. KURZON entre silencio intencionado y silencio no intencionado, el Prof. Ennio BONEA, Il silenzio, en «La retorica del silenzio. Atti del Convegno Internazionale Lecce, 24-27 ottobre 1991», Lecce, 1994, págs. 88-90, habla de la existencia de un silencio elección frente a un silencio imposición: "In termini correnti il silenzio può essere una scelta soggettiva oppure incosciente, che determina l'astensione dalla parola; ovvero è una condizione imposta, extrasoggettiva, una inibizione statuita da norme. [...] Valga una indicazione esemplificativa che, priva di didascalie pleonastiche, sintetizzi, senza presunzioni di esaustività, il silenzio imposto o scelto. Quello impositivo: 1) da alcune patologie e dalla morte; 2) dalla legge e dalla burocrazia, corretto dalla norma «silenzio-assenso», contrabilanciato ambiguamente da questa «silenzio-rifituto»; 3) dalle regole monacali degli esercizi spirituali; 4) dai regolamenti militari che non consentono al subordinato di eccepire o da quello dei collegi, da osservarsi come punizioni, in piedi dinanzi ad un muro, durante la ricreazione dei compagni; 5) dall'invito sollecitato cortesemente dall'arbitro negli incontri di tennis. Quello scelto, o volontario: 1) dinanzi ad un teorema scientifico o durante una partita a scacchi; 2) dinanzi alla spettacolarità di una esecuzione artistica; 3) dall'omertà, che potrebbe parere legittimo, ma non lo è, quando sia la paura ad imporlo».

32 KURZON, ult. op. cit., pag. 33. 
son de ánimo tímido, se turban fácilmente, incluso aunque puedan contribuir con algo respondiendo a la cuestión; mientras que la Prof. SIFIANOU ${ }^{33}$ ha advertido que aquellos actos que constituyen una amenaza para el lado negativo del hablante -como, por ejemplo, aceptar que le den las gracias-, pueden en muchas ocasiones no ser realizados a causa de su timidez o de la turbación que le ocasionan. Por su parte, el Prof. KURZON ${ }^{34}$ también indica que, en otras casiones, el silencio de un sujeto al cual le ha sido dirigida una cuestión puede ser debido al hecho de que se encuentre demasiado turbado como para admitir su propia ignorancia ${ }^{35}$; es más, afirma igualmente, que el silencio puede en muchos casos ser el resultado del temor de que quien nos ha preguntado descubra algo sobre nosotros -incluido el hecho de que somos tímidos o ignorantes. Por su parte, los Profs. ARGYLE, FURNHAM y GRAHAM ${ }^{36}$ indican que aquel a quien se le ha planteado una cuestión puede permanecer en silencio en situaciones que conllevan para él un importante estrés ${ }^{37}$; este patrón de conducta -añaden estos autores- se produce básicamente en situaciones en que existe un importante estado de ansiedad, situación que varía según las condiciones y el momento ${ }^{38}$. De un modo parecido se ha expresado el Prof. MILLER ${ }^{39}$, quien mantiene que cuando una persona se encuentra en una situación que le genera un senti-

${ }_{33}$ Maria SIFIANOU, Do we need to be silent to be extremely polite? Silence and FTAs, en «International Journal of Applied Linguistics», vol. 5, 1995, pág. 103.

${ }^{34}$ KURZON, ult. op. cit., pág. 33.

35 Uno de los casos típicos viene representado por el alumno al cual su profesor le plantea una cuestión, tal y como ha indicado el Prof. D. KURZON, The Right of Silence: a socio-pragmatic model of interpretation, en «Journal of Pragmatics», vol. 23, 1995, pág. 61: «[...]We have seen that since people are often embarrassed when they have to admit their ignorance, they can hide their ignorance behind a wall of silence in situations where they are not forced to speak. A schoolchild sitting at the back of the class often plays this game. When asked by the teacher to respond, s/he remains silent, and unless the teacher has time and patience, the pupil is not coaxed into giving an answer, or into admitting ignorance $[\ldots] »$. 1981.

${ }_{36}$ M. ARGYLE, A. FURNHAM, J. A. GRAHAM, Social Situations, Cambridge,

37 Estas situaciones serían, en palabras del Prof. KURZON, Discurse of Silence, Amsterdam, 1998, pág. 35: «[...](1) intimacy, (2) assertiveness, (3) focus of attention, (4) complex social routines and etiquettes, (5) failure and rejection, (6) pain and, lastly, (7) loss and bereavement.

${ }_{38}$ Ver ARGYLE, FURNHAM y GRAHAM, op. cit., pág. 320. En cualquier caso, el Prof. KURZON, ult. op. cit., pág. 35, es plenamente consciente de que -sin duda- existen también personas que, en situaciones estresantes como los aquí planteadas, en vez de refugiarse en el silencio, utilizan el discurso para liberar las tensiones, normalmente además en un tono bastante elevado, cuando no recurriendo directamente a gritos y chillidos.

39 S. MILLER, The Shame Experience, Hillsdale, 1985. 
miento de vergüenza, su Yo se está moviendo en una doble dirección -hacia afuera, situándose hacia el mundo exterior; y hacia dentro mediante una preocupación precisamente sobre ese movimiento hacia el exterior. El movimiento hacia el exterior se puede ejemplificar con el hecho de sonrojarse, el cual no puede ser ocultado, aunque dicha persona puede intentar cubrir parte de ese sentimiento de vergüenza desviando la mirada, o dejando de hablar-mediante el silencio; a este respecto, el Prof. BRUNEAU señala que ante estas situaciones, la otra parte en la conversación debe proceder a asumir un rol más activo todavía, pues si ella pasa a asumir igualmente una postura silenciosa, la situación de incomodidad y embarazo de la persona que ha guardado silencio suele incrementarse en gran medida ${ }^{40}$.

En todo caso, en estos supuestos en que nos encontremos ante un silencio no intencionado ${ }^{41}$, éste -como ha indicado el Prof. KUR$\mathrm{ZON}^{42}$ - no puede ser interpretado como una alternativa al discurso, y por tanto es imposible otorgarle ningún tipo de significado; es decir, la cuestión del silencio y su eventual significado sólo es posible plantearla cuando dicha conducta silenciosa se trate de una conducta intencionada y voluntaria por parte de aquél a quien le ha sido planteada una determinada cuestión o pregunta.

En consecuencia, todo silencio -lógicamente, siempre que sea intencionado- tiene, sin duda, un significado ${ }^{43}$, siendo en realidad el

40 Thomas J. BRUNEAU, Communicative Silences: Forms and Functions, en "The Journal of Communication», vol. 23, 1973, pág. 34.

41 Junto a estos silencios de origen psicológico no intencionales, lo cierto es que -como ha puesto de relieve el Prof. Thomas J. BRUNEAU, op. cit., págs. 33-34-, existen toda otra serie de emociones las cuales también se plasman en muchas ocasiones en un comportamiento silencioso, si bien en estos casos desde luego no es posible hablar de un silencio «no intencionado»: «Often, deep emotional states are expressed in silence. Intense grief, sorrow, and great disappointment are quiet states -words are difficult to find. Ritualized communications seem to find forms for allowing expression in such situations. Ritual in these situations apears to be very important because it offers some semblances of reality to persons too deep in ambiguous, mental silences. Perhaps one of the greatest insults is for friends not to at least attempt to show concern for a person in deep sorrowful or disappointing silence. Deep vengeance, jealously and resentment can also be very silent -before expressive eruption. Guilt, shame, and periods of penance are often silent conditions for both those experiencing them and those observing the judged wrong-doer. The deepest fears and most intensive joys are wordless -or undifferentitated, repetitive sounds. In short: silence is the language of all strong passions: love, anger, surprise, fear».

42 KURZON, ult. op. cit., pág. 36.

43 En concreto, Dennis KURZON, Discourse of Silence, Amsterdam, 1998, pág. 25, argumenta del siguiente modo: «[...]On being asked a question, the addressee has been given a verbal stimulus, but s/he has a choice between speech and silence as the answer. This choice creates meaning, thus silence has meaning. If so -and I think that 
problema determinar cómo ha de ser interpretado dicho silencio por la persona frente a quien se ha mantenido ${ }^{44}$, o incluso por un observador, teniendo en cuenta el específico contexto en el cual se ha producido, pues como afirmó el Prof. KURZON: «The question we must address is how the interpreter of the silence -the addresser or questioner, or even the neutral observer (the linguist in the present case)arrives at the meaning of the silence in a specific context, that is to say, what the assertion would have been, had the addressee spoken, or had replied to the question [...] ${ }^{45}$, pues es innegable -como ha señalado el Prof. A. HUSS- que: «Il paraît difficile élaborer une théorie générale du silence, alors que sa signification dépend des circonstances particulières de chaque cas ${ }^{46}$, mientras que la Prof. MONTIGLIO viene a poner el acento en el hecho de que la idea del «Silencio» no es universal, ni inmutable, sino que es específica de cada cultura: "It's now widely accepted that certain notions that we would tend to conceive as universal and immutable are in fact culturally specific. Silence is one of them [...]. Precisely because silence is culturally specific, its usage within a given society may be misunderstood by strangers ${ }^{47}$.

this assumption is generally accepted, we must ascertain firtsly whether silence is regarded as an act and whether its meaning may be derived from equivalent speech acts following Searle's approach. If an act is the deliberate activity on the part of an individual, then an addressee's decision to remain silent is such an act. Since the alternative to this act of silence is speech, then we may say that such silence is also a speech act. Of course, not all acts are deliberate; in fact we all find ourselves every day doing things -and saying things we do not intend. One can be silent without intending to be so, as we shall see. But, as mentioned already in the previous chapter, the intentional act is taken as the paradigmatic case».

${ }_{44}$ Esta misma idea es también defendida por el Prof. Domenico CARZO, Il diritto come retorica dell'interazione, Milán, 1992, pág. 49.

45 Dennis KURZON, Discourse of Silence, Amsterdam, 1998, pág. 26. Similar a ésta es la opinión mantenida por el Prof. Fernando POYATOS, Nonverbal Communication across disciplines. Vol. I: culture, sensory interaction, speech, conversation, Amsterdam, 2002, págs. 276-277, quien afirma: «Most silences and stills contain an eloquent facial expression or motionless manual gesture, and obviousl that is what must be translated when nothing else follows verbally [...]. In other words, very rarely does a brief conversational silence communicate nothing, therefore the interpreter may need to verbalize it, and that decision rest on his or her professional competence. Naturally, in a radio broadcast, where the speaker is not visible, an | emotional silence should be verbally identified by the interpreter, for the radio listeners must be given the reason for that silence. In other words, we could affirm, as a basic norm, that the interpreter, rather than turning a silence into words the speaker did not say, must discern between the silence that wants to express something and the one that wants to conceal it».

46 A. HUSS, Les modes non formels d'expression de la volonté en droit privé luxemborgeois, en «Travaux de l'Association Henri Capitant. Vol XX: Les Modes non Formels d'Expression de la Volonté», Paris, 1972, pág. 70.

${ }^{47}$ S. MONTIGLIO, Silence in the Land of Logos, Princeton, 2000, pág. 3. 
III.- Es precisamente el ámbito del Derecho, uno de aquellos en los cuales es posible apreciar con mayor claridad este carácter ambiguo del Silencio ${ }^{48}$, pues como ya puso claramente de relieve la Prof. Sara Maria GORETTI «uno di questi problemi scomodi è il problema del silenzio: problema ambiguo per eccelleza, in quanto il fenomeno del silenzio si configura certamente sotto il profilo della negatività (non parlare, non dire nulla), ma altrettanto bene sotto quello positivo della reticenza, della riserva mentale, della pavidità sino a presentarsi sotto il significativo e tragico aspetto dell'omertà. Problema perciò polivalente nelle soluzioni, dato il suo carattere di bifrontismo dialettico: il profilo negativo sembra avvalorare la tesi della insignificanza del fenomeno e quindi della sua problemática [...]; d'altra parte, il profilo positivo ripropone sul piano giuridico e su quello etico, le problematiche che si addentrano nei cosiddetti casi di coscienza, destinati ad offrire ricca materia drammatica alla letteratura di tutti i tempi, e sul piano dommatico-speculativo ripropone soluzioni nella singolarità della casistica oppure nel tentativo di rintracciare una teoria specifica del fenomeno stesso ${ }^{49}$.

En todo caso, ha de precisarse igualmente que cuando se plantea el problema jurídico del Silencio, éste ha de ser entendido no sólo como la falta de palabra -oral o escrita-, sino como la ausencia de cualquier acto o comportamiento del cual fuera posible deducir una determinada manifestación de voluntad, pues no sólo se habla con la lengua y por medio de la palabra oral o escrita, sino que también se hace con los ojos, con las manos, con la mímica con los gestos ${ }^{50}$; es decir, tal y como ya indicó el Prof. GABBA «la questione [...] intorno agli effetti del silenzio concerne propriamente e soltanto il silenzio assoluto di fronte a un atto altrui, che darebbe occasione di risposta, o di opposizione. Quel silenzio, cioè, che non è incidente in una dichiarazione di volontà, e non concorre nè con un atto o fatto che ad una dichiarazione di volontà equivalga, nè con una omissione, cioè col non esercizio di un diritto qualunque durante il termine fissato sia dalla legge, sia dal contratto, sia dalla sentenza del giudice» ${ }^{51}$.

48 Ver Roger NERSON, op. cit., pág. 401; Dennis KURZON, op. cit., pág. 5; Alfonso TESAURO, Il silenzio e l'omissione nella teoria degli eventi giuridici, en "Studi in onore di Federico Cammeo», vol. II, 1933,pág. 538.

${ }^{49}$ Maria Sara GORETTI, Il problema giuridico del silenzio, Milán, 1982, pág. 2

50 Ver, en este mismo sentido, Felipe CLEMENTE DE DIEGO, El Silencio en el Derecho, Madrid, 1925, pág. 39.

51 Carlo Francesco GABBA, Del Silenzio nel Diritto Civile, en «Nuove Questioni di Diritto Civile», vol. I, Turín, 1912, pág. 98. En esta misma línea se han manifestado el Prof. Carlos FERREIRA DE ALMEIDA, Texto e enunciado na Teoria do Negócio Jurídico, Coimbra, 1992, pág. 715; el Prof. Pierre GODÉ, Volonté et Manifestations Tacites, 
Por otro lado, en las fuentes jurídicas romanas es posible encontrar numerosos fragmentos en los cuales se plantea precisamente la cuestión del valor a atribuir a la conducta silenciosa mantenida por un sujeto, los cuales se hallan referidos además a las más diversas ramas del ordenamiento: derecho de familia ${ }^{52}$, derechos reales ${ }^{53}$, sucesiones $^{54}$, derecho procesal ${ }^{55}$, derecho público ${ }^{56}, \ldots \mathrm{y}$, por supuesto, al derecho contractual ${ }^{57}$,

Una primera cuestión que ha de plantearse a la hora de analizar todos estos textos es si en la base de los mismos es posible encontrar alguna regla o principio aplicable con carácter general a toda hipótesis de silencio, incluidos aquellos supuestos contemplados en el campo contractual. En nuestra opinión, y a diferencia de lo que sucede en Derecho Canónico, donde la ley 43 contenida entre las reglas del Derecho del Libro VI de las Decretales establece de modo categórico "qui tacet consentire videtur», en Derecho Romano no existe tal principio, pues el conocido texto contenido en D. 50.17.142, donde Paulo afirma "Qui tacet, non utique fatetur: sed tamen verum est eum non negare» no tiene tal alcance general, pues dicho texto fue extraído del libro LVI del Comentario de Paulo al Edicto del Pretor, cuyo lema era "De confesiis et indefensis», y el cual tal y como resulta de la «Palingenesia Iuris Civilis» de Otto Lenel ${ }^{58}$ aparecía justo a continuación de otro fragmento que también se nos ha conservado en el Digesto:

\section{Confessus pro iudicato est, qui quodammodo sua sententia damnatur ${ }^{59}$ \\ 692. Qui tacet, non utique fatetur: sed tamen verum est eum non ne- gare.}

En consecuencia, de la lectura conjunta de ambos textos, tal y como deberían aparecer originariamente en la obra de Paulo, es fácil

Paris, 1977, págs. 22-23; o la Prof. Ma Dolores DÍAZ-AMBRONA BARDAJI, El Silencio en la Teoría del Negocio Jurídico (notas a la sentencia del Tribunal Supremo de 19 de diciembre de 1990), en "Actualidad Civil», 1991, pág. 670.

52 Ver D. 1,5,11; D. 1,7,5; D. 23,1,12, pr.; D. 23,1,7,1; C. 5,4,5.

53 Ver D. 10,3,28.

54 Ver D. 21,2,12; D. 36,1,37,pr.

55 Ver: C. 2,55,5,1.

56 Ver D. 50,1,2,pr.

57 Ver: D. $14,6,12$; D. $14,6,16$; D. $17,1,18$; D. $17,1,40$; D. $17,1,53$; D. $17,1,62$; D. 19,2,13,11; D. 12,2,14.

58 Otto LENEL, Palingenesia Iuris Civilis, Tomo I, Leipzig, 1889 (reimpr. Aalen, 2000), col. 1073.

59 D. 42.2 .1 (PAUL., libr. LVI ad Edictum). 
apreciar que éste no buscó indicar ningún principio aplicable con carácter general al problema del silencio, sino que simplemente pretendió precisar dos situaciones diversas: por un lado, la del confessus, el cual resulta «iudicatus, quadammodo sua sententia damnatur»; mientras que el tacens, a diferencia de aquel, busca con su mutismo evitar cualquier tipo de responsabilidad.

Por otro lado, de la lectura de todos aquellos textos de las fuentes jurídicas romanas en los cuales se plantea la situación de un sujeto que ha mantenido una determinada conducta silenciosa frente a otro $\mathrm{u}$ otros sujetos ${ }^{60}$, se evidencia la existencia de soluciones totalmente divergentes, en ocasiones el silencio equivale a consentimiento y en otras asume un valor totalmente negativo; es decir, tal y como ha señalado la Prof. Huguette JONES «l'examen de l'ensemble des solutions apportées à notre problème dans les matières qui se rattachent au patrimoine permet d'aboutir cette fois à une certitude: le silenceréponse n'y a pas fait l'objet d'une transposition unique systemátique, mais une grande souplesse a présidé à son interprétation ${ }^{61}$, si bien coincidimos con la Prof. Gema TOMÁS, en su opinión de que «el Derecho civil de contratos, a diferencia de otros sectores del ordenamiento, como el Derecho administrativo, no se ha enfrentado al silencio con normas jurídicas, sino más bien con principios que se han ido configurando a lo largo del tiempo» ${ }^{62}$.

En cualquier caso, es innegable la existencia de textos -como D. 19.2.13.1163 - donde el silencio, esto es, la condcuta total y absolutamente pasiva mantenida por un sujeto conlleva la expresión de una determinada voluntad. Ahora bien, es imprescindible proceder a buscar cuál esla razón o el fundamento que se encuentra detrás de los mismos, pues si dichos efectos jurídicos se producen respecto a tal individuo que ha mantenido esa determinada postura totalmente pasiva, es innegable que los mismos no pueden derivar de la realización por su parte de algún tipo de declaración de voluntad a través del silencio, sino que la fuente de ellos no puede ser otra sino la ley, la norma jurídica. En consencuencia, defendemos la posición de que el silencio no puede constituir una auténtica declaración de voluntad ${ }^{64}$,

60 Ver supra notas 54-59.

${ }^{61}$ Huguette JONES, Le silence utilisé comme réponse en droit romain, en «Latomus», vol. XLVIII, 1989., pág. 18.

${ }^{62}$ Gema TOMÁS, Fuentes jurídicas del principio "qui tacet consentire videtur». Realidad jurídica versus difusión social, en «R.I.D.A.», vol. L, 2003, pág. 384.

${ }_{63}$ Ver José Antonio MARTÍNEZ VELA, Régimen jurídico de la tácita reconducción en Derecho Romano y su Proyección en Derecho Actual, Madrid, 2011, págs. 162-222.

${ }^{64}$ Idéntica opinión es mantenida por el Prof. Salvatore DI MARZO, Istituzioni di 
pues cuando aparentemente se anudan algún tipo de efecto jurídico a una conducta omisiva, dichos efectos derivan en realidad más que de esa conducta pasiva, de la previsión contenida en la norma jurídica o en el previo acuerdo de las partes ${ }^{65}$.

Es decir, en todos aquellos textos en los cuales se hace referencia al denominado "Problema del Silencio», en realidad, se está ante una "Declaración PRESUNTA» ${ }^{66}$, en el sentido de que es la ley la que presume en caso de producirse un determinado supuesto de hecho -la inactividad de un sujeto ante una determinada conducta mantenida con carácter previo por otro individuo- un concreto efecto jurídico ${ }^{67}$.

IV.- En cuanto a cómo ha sido afrontado el problema del silencio en las modernas legislaciones civiles, hemos de señalar en primer lugar que en nuestro país, el Código Civil se limita en su art. 1258 a indicar que «los contratos se perfeccionan por el mero consentimiento, y desde entonces obligan [...]», señalando su art. 1261 como requisito para la existencia del contrato el «consentimiento de los contratantes ${ }^{68}$, pero no conteniéndose en la Sección $1^{\mathrm{a}}$, Capítulo II del Titulo II del Libro IV dedicada específicamente al «Consentimiento» ninguna disposición referente a la eventual forma que puede revestir la declaración de voluntad; en realidad, el artículo 1262 se limita a establecer el momento en el cual se entiende prestado el consenti-

Diritto Romano, Milán, 1938, págs. 65-66. En esta misma línea de negar al silencio el carácter de auténtica manifestación de voluntad se encuentra el Prof. Giuseppe BRANCA, Istituzioni di Diritto Privato ${ }^{6}$, Bolonia, 1978, pág. 64, quien viene a afirmar que el silencio no es manifestación de voluntad, pues en aquellos casos en los cuales parece que sirve como declaración afirmativa, son todas situaciones características, en las cuales existía una carga o una obligación (legal o convencional) de hablar para tener o para evitar ciertas consecuencias; casos, por tanto, en los cuales, como el comportamiento no es libre, se encuentran -afirma el Prof. BRANCA- fuera del campo del negocio jurídico.

${ }^{65}$ Ver también Pietro BONFANTE, Corso di Diritto Romano. Vol. IV: le obbligazioni, Milán, 1979, págs. 304-305; Francesco CARNELUTTI Sistema de Derecho Procesal Civil. Vol. III: Actos del Proceso, Buenos Aires, 1944, pág. 397. 58.

${ }^{66}$ Ver Eugene GAUDEMET, Teoría general de las obligaciones, México, 1974, pág.

${ }^{67}$ Esta opinión es también mantenida por el Prof. Cesare SANFILIPPO, Istituzioni di Diritto Romano ${ }^{9}$, Messina, 1996, pág. 95; por el Prof. Werner FLUME, El Negocio Jurídico, Madrid, 1998, págs. 153-154; o por los Profs. José Antonio DORAL y Miguel Angel DEL ARCO, op. cit., pág. 101.

68 En concreto, el art. 1261 dispone: «No hay contrato sino cuando concurren los requisitos siguientes: $1^{\circ}$ Consentimiento de los contratantes. $2^{\circ}$ Objeto cierto que sea materia del contrato. $3^{\circ}$ Causa de la obligación que se establezca». 
miento, y en consecuencia nacida la obligación, pero sin hacer ninguna alusión a la forma de la declaración de voluntad, y aún menos al eventual significado o sentido del silencio ${ }^{69}$.

Ahora bien, dentro de nuestro ordenamiento jurídico existe una disposición en la cual sí se hace referencia expresa a la cuestión del Silencio, se trata de la Ley 20 de la Compilación del Derecho Civil Foral de Navarra ${ }^{70}$.

"El silencio o la omisión no se considerarán como declaración de voluntad, a no ser que así deba interpretarse conforme a la Ley, la costumbre o los usos, o lo convenido por las partes».

Es decir, el legislador navarro ha optado -como señala el Prof. Enrique RUBIO TORRANO- por el principio general de que el silencio o la omisión no pueden ser considerados como declaración de voluntad al faltarles en principio el vehículo de exteriorización o forma de expresión de la misma ${ }^{71}$; de manera que, en opinión de este mismo autor, el silencio sólo podrá ser valorado «como verdadera declaración de voluntad, que origina o modifica el negocio, cuando expresa o tácitamente se le atribuya el significado de aceptación ${ }^{72}$, es decir, cuando tal eficacia le haya sido atribuida, bien por la ley, bien por el acuerdo de las partes, bien por la costumbre o los usos existentes, pues con relación a estos últimos no podemos olvidar que la citada

${ }^{69}$ En concreto, el art. 1262 afirma: «El consentimiento se manifiesta por el concurso de la oferta y de la aceptación sobre la cosa y la causa que han de constituir el contrato. Hallándose en lugares distintos el que hizo la oferta y el que la aceptó, hay consentimiento desde que el oferente conoce la aceptación o desde que, habiéndosela remitido el aceptante, no pueda ignorarla sin faltar a la buena fe. El contrato, en tal caso, se presume celebrado en el lugar en que se hizo la oferta. En los contratos celebrados mediante dispositivos automáticos hay consentimiento desde que se manifiesta la aceptación».

${ }^{70}$ La Ley de Bases de 11 de mayo de 1888 que autorizaba al Gobierno para publicar un Código civil en España, estableció igualmente de modo expreso la pervivencia y validez del Derecho Foral existente en el momento de la redacción del citado Código, al disponer su artículo 5: «Las provincias y territorios en que subsiste derecho foral, lo conservarán por ahora en toda su integridad, sin que sufran alteración su actual régimen jurídico por la publicación del Código, que regirá tan sólo como supletorio en defecto del que lo sea en cada una de aquellas por sus leyes especiales. El título preliminar del Código, en cuanto establezca los efectos de las leyes y de los estatutos y las reglas generales para su aplicación, será obligatorio para todas las provincias del Reino [...]»; reconociendo en consonancia con lo anterior el art. 13 del vigente Código civil la plena vigencia el Derecho Foral en su territorio respectivo, teniendo en éstos -con la excepción del Título Preliminar- sólo carácter supletorio las disposiciones del Código Civil.

71 Enrique RUBIO TORRANO, Comentarios al Fuero Nuevo. Compilación del Derecho Civil Foral de Navarra, Pamplona, 2002, pág. 59.

72 Enrique RUBIO TORRANO, op. cit., pág. 59. 
Compilación del Derecho Civil Foral de Navarra les otorga el primer lugar dentro de la prelación de fuentes ${ }^{73}$.

Por tanto, dada esta ausencia de previsión legislativa expresa válida con carácter general, se ha de dirigir la mirada hacia la doctrina y la jurisprudencia, si bien -tal y como pone de relieve la Prof. VALPUESTA FERNÁNDEZ- la cuestión del silencio no ha sido un tema pacífico en la doctrina española: «sobre el valor del silencio como expresión de una voluntad se han mantenido posiciones muy dispares, que van desde admitir su relevancia, recordando el viejo aforismo de que quien calla otorga, a negar toda trascendencia en este sentido, apoyado en la «nada» que implica esa conducta» ${ }^{74}$.

Uno de los extremos vendría representado por la Sentencia del Tribunal Supremo de 27 de abril de 1945, en la cual se defiende la idea de que si el destinatario de la oferta contractual no responde de ningún modo y se limita a callar sin desplegar actividad alguna consiente $^{75}$; situándose en el extremo contrario aquellos que niegan en todo caso al silencio la aptitud para dar forma a una declaración de voluntad, idea que aparecía ya en el Derecho histórico español, en concreto, en «Las Partidas», cuya Regla XXIII del Título XXXIV de la Partida VII, disponía: "E aun dixeron que aquel que calla non se entiende que siempre otorga lo quel dize, maguer non responda: mas esto es verdad que non niega lo que oye».

Ahora bien, en la actualidad puede afirmarse que la mayor parte de la Doctrina defiende opiniones intermedias, en el sentido de que por un lado se niega al silencio la aptitud con carácter general para dar origen a un contrato -como ha señalado el Prof. Carlos CUADRADO PÉREZ «el silencio, como regla general, no puede ser considerado como forma de manifestar la voluntad contractual» ${ }^{76}-$, pero por otro lado se procede a establecer excepciones y matizaciones a di-

${ }^{73}$ En concreto, la Ley 2 de dicha Compilación del Derecho Civil Foral de Navarra dispone: "En Navarra la prelación de fuentes de derecho es la siguiente: 1) La costumbre.

2) Las Leyes de la presente Compilación. 3) Los principios generales del Derecho navarro.

4) El Derecho supletorio".

Mientras que la Ley 3 procede a definir qué se entiende por «costumbre», así como a establecer su marco de vigencia y aplicación: «La costumbre que no se oponga a la moral o al orden público, aunque sea contra ley, prevalece sobre el Derecho escrito. La costumbre local tiene preferencia respecto a la general».

${ }^{74} \mathrm{M}^{\mathrm{a}} \mathrm{R}$. VALPUESTA FERNÁNDEZ, Derecho Civil. Contratos y Obligaciones ${ }^{3}$, Valencia, 1998, pág. 359.

${ }^{75}$ Idéntica opinión fue mantenida en las sentencias del T.S. de 18 de julio y 26 de noviembre de 1948, si bien la misma cayó rápidamente en desuso.

${ }^{76}$ Carlos CUADRADO PÉREZ, op. cit., pág. 366. 
cha regla general; es decir, tal y como ya señaló el Prof. CASTÁN TOBEÑAS «el problema no está, pues, en decidir si el silencio puede ser expresión del consentimiento, sino en determinar bajo qué condiciones puede aquél ser interpretado como tácita manifestación de ese consentimiento ${ }^{77}$. Precisamente, en estas ideas incide la Sentencia del Tribunal Supremo de 24 de enero de $1957^{78}$ al señalar «que el consentimiento, que constituye el alma del contrato, puede ser manifestado de modo expreso, por una o ambas partes, cuando éstas emiten una explícita declaración de voluntad dirigida a la constitución del negocio, o bien tácitamente, cuando de su comportamiento o de sus declaraciones resulta implícita su aquiescencia, no debiendo confundirse con el consentimiento tácito el simple silencio, pues si el contrato es un acuerdo entre dos o más personas, dirigido a constituir, regular o disolver un vínculo jurídico, este acuerdo no puede resultar de un comportamiento meramente negativo de una de las partes, de un estado de simple inercia, cual es el silencio absoluto, sino que debe manifestarse con palabras o con hechos, más cuando el silencio pueda juntarse a hechos positivos, precedentes a una actividad anterior de la parte silenciosa, o a particulares situaciones subjetivas u objetivas, también este silencio cualificado puede concurrir como elemento útil para apreciar la voluntad de la parte misma»; así como el voto particular efectuado por el Magistrado Antonio Fernández Rodríguez a la Sentencia de 19 de diciembre de $1990^{79}$, donde podemos leer: «[... ]ciertamente el conocimiento no equivale a consentimiento, ni por modo general puede afirmarse que el silencio equivale a una declaración, pues el que calla en realidad ni afirma ni niega («qui tacet non utique fatetur»), sin embargo tampoco es lícito considerar el silencio como indiferente para el Derecho, al no caber duda que en algunos casos el silencio puede ser interpretado como consentimiento, es decir como manifestación de una determinada voluntad («qui tacet consentire videtur»), de manera que el problema, en materia de silencio, no está en decidir si puede ser expresión de consentimiento, sino en determinar bajo qué condiciones puede aquél ser interpretado como tácita manifestación de ese consentimiento».

En conclusión, compartimos con relación al Derecho español las conclusiones a las que llegó el Prof. Federico DE CASTRO Y BRAVO ${ }^{80}$, en el sentido de que el silencio, por sí mismo, no significa más que la

77 José CASTÁN TOBEÑAS, Derecho Civil Español, Común y Foral. Vol. II ${ }^{14}$, Madrid, 1984, pág. 753.

78 RJ 367/1957.

79 RJ 10287/1990.

${ }^{80}$ Federico DE CASTRO Y BRAVO, El Negocio Jurídico, Madrid, 1985, pág. 69. 
carencia de expresión y de la nada no cabe sacar ninguna consecuencia positiva. Ahora bien, dicho silencio podrá adquirir valor significativo, pero sólo en conexión con otros hechos o actos, y entonces como parte de una completa conducta expresiva; es decir, para poder valorar al silencio como una auténtica declaración de voluntad es preciso que con carácter previo le haya sido atribuido tal significado de aceptación, lo cual se produce en una serie muy concreta y limitada de supuestos, básicamente dicha vinculación derivará, bien del acuerdo de las partes, bien de una previsión expresa de la ley, solución idéntica a la que hemos defendido para el Derecho Romano.

V.- En cuanto a la situación en Derecho Comparado, hemos de poner de relieve en primer lugar que en los tres sistemas jurídicos más representantivos del Derecho Continental -Francia, Alemania e Italia-, sus respectivos códigos civiles -al igual que sucede en nuestro país- no se han planteado de modo expreso esta cuestión ${ }^{81}$, habiendo llegado la doctrina y la jurisprudencia respectiva de cada uno de estos países a conclusiones muy similares a las alcanzadas en España: el silencio por sí mismo no equivale a consentimiento, salvo cuando así aparezca determinado, bien por el acuerdo de las partes, bien por la ley, bien por los usos y costumbres comerciales.

En cambio, es precisamente en el marco de los modernos intentos de codificación supranacional en materia contractual y comercial, así como en aquellos países en los cuales se ha procedido en los últimos años a compilar y codificar su ordenamiento jurídico civil donde es posible encontrar referencias explícitas al significado que debe atribuirse al mismo, siendo realmente paradigmática de esta tendencia la situación existente en las modernos códigos civiles promulgados en la

${ }^{81}$ En concreto, el art. 1101 del Código civil francés al definir qué se entiende por contrato se limita a afirmar: «Le contrat est une convention par laquelle une ou plusieurs personnes s'obligent, envers une ou plusieurs autres, à donner, à faire ou à ne pas faire quelque chose», mientras que la Sección I del Capítulo II del Título III dedicada precisamente al análisis del «Consentement», se limita al análisis de los Vicios del Consentimiento. Por su parte, en la amplia sección dedicada por el BGB al análisis de la «Willenserklärung» (§§ 116-144) no se hace ninguna alusión al valor a atribuir al silencio, situación prácticamente idéntica a la contemplada por el Código civil italiano de 1942, cuyo art. 1326 que regula los requisitos a los cuales se somete la conclusión de un contrato no se plantea esta cuestión, centrándose en otras como: el momento en el cual se entiende perfeccionado el contrato (primer párrafo), el plazo en el cuál puede efectuarse válidamente la aceptación de la oferta contractual (párrafos segundo y tercero), necesidad para el aceptante de sujetarse -en su caso- a la forma prescrita por el oferente (párrafo cuarto), y, por último, la necesidad de coherencia entre oferta y aceptación (párrafo quinto). 
última década del siglo pasado en los distintos países que surgieron en la Europa Oriental como consecuencia de la desmembración de la antigua U.R.S.S. ${ }^{82}$.

Del análisis del conjunto de dicha legislación se evidencia, en primer lugar, que el silencio sólo es admisible en cuanto forma de aceptación de una determinada oferta contractual, negándosele siempre y en todo la capacidad de poder constituir la fuente de una oferta válida de contrato. Es igualmente un punto común en toda esta normativa que el comportamiento omisivo no puede interpretarse con carácter general como un mecanismo válido para la citada aceptación de una oferta, sino que únicamente podrá atribuírsele dicha eficacia en aquellos supuestos en los cuales dicha conducta omisiva aparezca rodeada de otra serie determinada de condiciones o circunstancias previstas de modo expreso por cada ordenamiento jurídico.

Así, en el marco de los «The Unidroit Principles of International Commercial Contracts» ${ }^{83}$, éste es precisamente el principio establecido por el primer apartado de su artículo 2.1.6, el cual dispone:

${ }^{82}$ Ver: Carlos TAIBO, La disolución de la URSS: una introducción a la crisis terminal del sistema soviético, Barcelona, 1994; Ricardo M. MARTÍN DE LA GUARDIA, La Unión Soviética: de la perestroika a la desintegración, Madrid, 1995; Ricardo M. MARTÍN DE LA GUARDIA, Crisis y desintegración: el final de la Unión Soviética, Barcelona, 1999.

${ }_{83}$ Ver: AA.VV., Principi per I contratti commerciali internazionali e il sistema giuridico latinoamericano, Padova, 1996; José María ABASCAL ZAMORA, Los principios sobre los contratos comerciales internacionales de UNIDROIT, en "Derecho de los Negocios», 1997, págs. 11-22; Michael Joachim BONELL y Franco BONELLI, Contratti commerciali internazionali e principi unidroit, Milán, 1997; M $^{\mathrm{a}}$ del Pilar PERALES VISCASILLAS, El derecho uniforme del Comercio Internacional: los principios de Unidroit (ámbito de aplicación y disposiciones generales), en «Revista de Derecho Mercantil», 1997, págs. 221298; Luciano PONTIROLI, La protezione del «contrente debole» nei Principles of International Commercial Contracts di UNIDROIT: much ado about nothing?, en "Giurisprudenza commerciale», 1997, págs. 566-606; AA.VV., Los principios de UNIDROIT, ¿un derecho común de los contratos para las Américas?: actas del Congreso Interamericano sobre los Principios de UNIDROIT, Roma, 1998; Boris KOZOLSCHYK, The UNIDROIT principles as a model for the unification of the best contractual practices in the Americas, en «The American Journal of Comparative Law», 1998, págs. 151-ss.; Miguel UNCETA LABORDA, Los principios de UNIDROIT en la práctica de la Corte Internacional de Arbitraje de la CCI, en «Revista de la Corte Española de Arbitraje», 2000-2001, págs. 285-300; Michael Joachim BONELL, I principi UNIDROIT nella pratica: casistica e bibliografia risguardanti, Milán, 2002; AA.VV., Comentarios a los principios de unidroit para los contratos del comercio internacional ${ }^{2}$, Pamplona, 2003; Michael Joachim BONELL, UNIDROIT Principles 2004 - The New edition of the Principles of International Commercial Contracts adopted by the International Institute for the Unification of Private Law, en «Uniform Law Review», 2004, págs. 5-40; José Luis SIQUEIROS, Los nuevos principios de Unidroit 2004 sobre contratos comerciales internacionales, en «Revista de Derecho Privado», vol. 11, 2005, págs. 128-145; R. ZIMMERMANN, Die Unidroit-Grunregeln der internationalen Handelsverträge 2004 in vergleichender Perspektive, en «ZEuP», 
«1. Constituirá una aceptación toda declaración o cualquier otro acto del destinatario que indique su asentimiento a una oferta. Ni el silencio ni la conducta omisiva, por sí solos, implican una aceptación.

2. La aceptación de la oferta surte efectos cuando la indicación de asentimiento llega al oferente.

3. No obstante, en virtud de la oferta, o de las prácticas que las partes hayan establecido entre ellas o de los usos, el destinatario puede indicar su asentimiento ejecutando un acto sin notificación al oferente, la aceptación surte efectos cuando se ejecute dicho acto» ${ }^{84}$.

Otro tanto sucede en los «Principios de Derecho Contractual Europeo» ${ }^{85}$, en concreto, por su artículo 2:20486:

2005, págs. 264-290; Michael Joachim BONELL, An International Restatement of Contract Law. The Unidroit Principles of International Commercial Contracts ${ }^{3}, 2005 ; \mathrm{Mi}-$ chael Joachim BONNELL, Un «Codice» internazionale del diritto dei contratti: I Principi UNIDROIT del contratto commerziali internazionali, Milán, 2006.

${ }^{84}$ Con relación al problema del silencio, compartimos plenamente las afirmaciones de la Prof. Pilar PERALES VISCASILLAS, en los «Comentarios a los Principios de Unidroit para los Contratos del Comercio Internacional», Pamplona, 2003, pág. 127: «[...]En relación con el silencio y la inacción los Principios adoptan el enfoque universalmente seguido en el derecho comparado (el valor neutral de esas figuras). No obstante, el precepto hace hincapié en las palabras, por sí solos, por lo que se está reconociendo a contrario que el silencio o la inacción pueden valer como aceptación. El problema no es tanto el reconocimiento de esas figuras, como el de determinar los factores que hacen que el silencio o la inacción puedan valer como aceptación. Desde luego, el oferente no puede forzar la perfección contractual al especificar en su oferta que el silencio o la falta de actuación del destinatario se reputa como aceptación o, con otros términos, ningún oferente puede mediante una mera frase en la oferta imponer el deber de hablar al destinatario [...]. Por el contrario, el silencio y la inacción podrán valer como aceptación en diversas circunstancias: cuando las partes así lo acuerdan (art. 1.1), cuando los usos o las prácticas establecidas entre los contratantes llevan a esa conclusión (art. 1.8) y cuando otros preceptos así lo reconocen (por ejemplo, arts. 2.11 y 2.9) [...]».

${ }_{85}$ Estos principios son el resultado del trabajo llevado a cabo por la «Comisión de Derecho Europeo de los Contratos», la cual está formada por un grupo de juristas provenientes de todos los Estados miembros de la Unión Europea bajo la presidencia del Prof. Ole Lando.

Con relación a esta cuestión pueden consultarse, entre otros Juan SÁNCHEZCALERO GUILARTE, Dictamen del Comité Económico y Social sobre la Comunicación en materia de Derecho contractual europeo, en «Revista de Derecho Bancario y Bursátil», vol. 89, 2003, págs. 427-429; María Paz SÁNCHEZ GONZÁLEZ, Las tendencias unificadoras del derecho contractual europeo, en «Revista de Derecho Privado», vol. 87, 2003, págs. 709-735; Guido ALPA, La armonización del derecho contractual y el proyecto de Código civil europeo, en «Revista de Derecho Patrimonial», vol. 11, 2003, págs. 25-30; Miguel Ángel MALO VALENZUELA, Los vicios de la voluntad en los principios de Derecho Contractual Europeo, en «Revista Crítica de Derecho Inmobiliario», 2005, págs. 887-926; Reiner SCHULZE, Deberes precontractuales y conclusión del contrato en el Derecho Contractual Europeo, en "Anuario de Derecho Civil», vol. 59, 2006, págs. 2958; Gabriel GARCÍA CANTERO, La tercera parte de los principios de Derecho contractual europeo, en "Revista Jurídica del Notariado», vol. 61, 2007, págs. 385-391.

${ }^{86}$ En cualquier caso, este artículo debe completarse con otros preceptos en base a 

mos",

«El silencio o la inactividad no constituyen aceptación por sí mis-

pudiéndose, sin duda, considerar como el antecedente de las anteriores normas, la Convención de Viena sobre Compraventa Internacional de Mercaderías ${ }^{87}$, de 11 de abril de 1980, aprobada en el marco de las Naciones Unidas y elaborada por la «Comisión para las Leyes del Comercio Internacional» (UNCITRAL) ${ }^{88}$, cuyo artículo 18.1 dispone:

«Toda declaración u otro acto del destinatario que indique asenti-

los cuales se viene a establecer que cuando concurren determinadas circunstancias, el silencio de una de las partes puede ser interpretado como una aceptación a la propuesta contractual.

Así, el art. 2:102 viene a establecer que la voluntad de las partes de vincularse contractualmente puede exteriorizarse no sólo a través de una declaración verbal o escrita, sino también por medio de su comportamiento, en el cual -lógicamente- se incluye también la conducta pasiva: "La voluntad de una parte de vincularse contractualmente se determinará a partir de sus declaraciones o su conducta, tal y como éstas fueran razonablemente entendidas por la otra parte».

${ }^{87}$ Con relación a la misma, puede consultarse la siguiente bibliografía: SCHLECHTRIEM, Uniform Sales Law. The UN Convention on Contracts for the International Sale of Goods, Viena, 1986; BIANCA y BONELL (coords.) Commentary on the International Sales Law. The 1980 Vienna Sales Convention, Milán, 1987; HONNOLD, Derecho Uniforme sobre Compraventa Internacional de Mercaderías (Convención de las Naciones Unidas de 1980), Madrid, 1987; AUDIT, La vente internationale de marchandises. Convention des Nations-Unies du 11 avril 1980, Paris, 1990; BIANCA (coord.), Convenzione di Vienna sui contratti di vendita internazionale e di beni mobili, Padua, 1991; ENDERLEIN y MASKOW, International Sales Law. United Nations Convention on Contracts for the International Sale of Goods-Convention on the Limitation Period in the International Sale of Goods. Commentary, 1992; MEDINA DE LEMUS, La venta internacional de mercaderías, Madrid, 1992; MING y NEUMAYER, Convention de Vienne sur les Contrats de Vente internationale de marchandises, Lausanne, 1993; GUARDIOLA SACARRERA, La compraventa internacional, Barcelona, 1994; ADAME GODDARD, El contrato de compraventa internacional, México, 1994; Luis DÍEZ PICAZO (dir.), La compraventa internacional de mercaderías, Madrid, 1998; VÁZQUEZ LEPINETE, Compraventa Internacional de Mercaderías. Una visión jurisprudencial, Pamplona, 2000; Javier SAN JUAN GRUCELAEGUI, Contrato de Compraventa Internacional de Mercaderías. Convención de Viena de 1980, y otros textos complementarios, Pamplona, 2005.

${ }_{88}$ Esta Comisión fue establecida por la Asamblea General de las Naciones Unidas en 1966 -en base a la resolución 2205(XXI) de 17 de diciembre. Con su creación, la Asamblea reconoció que las disparidades entre las leyes nacionales que regían el comercio internacional creaban obstáculos para ese comercio, considerando que mediante esta Comisión, las Naciones Unidas podrían desempeñar un papel más activo en la reducción o eliminación de esos obstáculos. En concreto, esta Comisión recibió el mandato general de fomentar la armonización y unificación progresivas del Derecho mercantil internacional, convirtiéndose desde entonces en el órgano jurídico central del sistema de las Naciones Unidas en el ámbito del derecho mercantil internacional. 
miento a una oferta constituirá aceptación. El silencio o la inactividad, por sí solos, no constituirán aceptación $»^{89}$.

Por otro lado, dentro de las legislaciones nacionales, el código civil de Rusia, de 21 de octubre de 1994, mantiene precisamente esta solución en su artículo 158:

«Le silence vaut expression de volonté de passer l'acte dans les cas prévus par la loi ou par l'accord des parties» ${ }^{90}$;

idéntica solución es mantenida por el código civil de la República de Lituania de 2001, en concreto, por el apartado $3^{\circ}$ de su artículo 1.64, dedicado al análisis de las distintas formas que puede revestir la declaración de voluntad:

"Silence may be deemed to be an expression of will exclusively in the cases established by laws or agreed upon by the parties to the transaction ${ }^{91}$;

o por el parágrafo 63 de los «General Principles of the Civil Code Act» de la República de Estonia, aprobada el 28 de junio de 1994:

«Silence shall be deemed a declaration of intention if so prescribed by law or an agreement of the parties» ${ }^{22}$;

así como, por último, por el apartado $3^{\circ}$ del artículo 294 del Código Civil de la República de Armenia, aprobado el 17 de junio de 1998:

«Silence shall be recognized as an expression of will to make a transaction in cases provided by a statute or agreement of the parties $»^{93}$.

${ }^{89}$ Es decir, tal y como ha señalado el Prof. Fabio ADDIS, Lettera di Conferma e Silenzio, Milán, 1999, pág. 302, este artículo negando que el silencio y la inactividad por sí mismos equivalgan a aceptación, en realidad está afirmando que si concurren determinadas circunstancias, también un comportamiento meramente omisivo puede servir como aceptación. En este mismo sentido se han expresado el Prof. Luis DIEZ PICAZO, La formación del contrato, en «Anuario de Derecho Civil», 1995, pág. 23, o el Prof. Burghard PILTZ, Compraventa Internacional. Convención de Viena sobre Compraventa Internacional de Mercaderías de 1980, Buenos Aires, 1998, pág. 59.

90 Traducción de Dusan KITIC, realizada con la colaboración de Omourtag PETKOV y Gregoire DIKOV.

91 Esta traducción al inglés es obra del propio Ministerio de Justicia Lituano, incluyéndose la misma en el marco de su página web.

${ }_{92}$ El texto en inglés de los «General Principles of the Civil Code Act» de la República de Estonia se debe a la labor desarrollada por el «Estonian Legal Language Centre».

${ }_{93}$ La traducción inglesa del Código Civil de la República de Armenia se inserta en el marco de las actividades llevadas a cabo por la «Deutsche Gesellschaft für Technische Zusammenarbeit»(GTZ). 
Ésta es, por otra parte, la misma solución prevista por el artículo 142 del código civil de Perú, de 24 de julio de 1984:

«El silencio importa manifestación de voluntad cuando la ley o el convenio le atribuyen ese significado»;

así como, por el Código Civil de Cuba ${ }^{94}$, en concreto, por el apartado $2^{\circ}$ de su artículo 49 , con relación al cual ha de ponerse también de relieve que el legislador cubano junto al silencio menciona de modo expreso a la "omisión» como circunstancia apta para hacer surgir la obligación -siempre, lógicamente, que se den las circunstancias legalmente previstas para ello:

«2.La omisión y el silencio tienen los efectos que determinan las normas jurídicas o, en su defecto, los que les conceden las partes en el acto jurídico de que se trate».

Ahora bien, llegados a este punto, no puede dejar de ser mencionado el hecho de que la legislación civil de la República Rusa, junto al citado artículo 158 que establece con carácter general que el silencio equivaldrá a consentimiento sólo cuando así lo prevea la ley o las partes, contiene otra disposición en la cual se regula también el valor que debe atribuirse al silencio. En concreto, se trata de su artículo 438, contenido en el capítulo XXVIII de su Título III, dedicado a regular la problemática que puede plantearse respecto a «La Conclusión de los Contratos», y el cual si bien ciertamente reitera la solución general que acabamos de indicar, añade una tercera circunstancia que permite la interpretación del silencio mantenido frente a una oferta contractual como aceptación de ésta: la existencia de algún tipo de uso comercial que lo prevea:

«1. L'acceptation est la réponse du destinatario de l'offre, c'est-àdire de son acquiescement à cette offre. L'acceptation doit être totale et inconditionnelle.

94 Con relación al Derecho Civil en Cuba hemos de reseñar que la pervivencia española en este ámbito fue muy superior a su soberanía sobre el territorio; así, la Proclama del Gobierno Militar de Cuba de 1 de enero de 1899 dispuso que: «[...]Quedarán en vigor el Código Civil y el Criminal existentes antes de finalizar la soberanía española, modificándose y cambiándose éstos, de tiempo en tiempo, cuando sea necesario para el mejor gobierno [...]». De este modo, el código civil español de 1889 permaneció formalmente vigente en la isla hasta el 16 de julio de 1987, fecha en la cual fue aprobado por la Asamblea Nacional cubana el nuevo código civil que vino a sustituirlo, si bien también es cierto que ya con anterioridad el legislador cubano había ido introduciendo diversas modificaciones a la legislación española, entre las que -por ejemplo- puede destacarse la derogación de todos los artículos relativos al régimen personal y económico de la familia contenidos en los Libros I, III y IV tras la promulgación el 14 de febrero de 1975 del denominado «Código de la Familia». Ver: Ángel CARRASCO PERERA, Código Civily Leyes Civiles cubanas, Cuenca, 2000. 
2. Le silence ne vaut pas acceptation, sauf si le contraire résulte de la loi, des usages de commerce, ou de rélations d'affaires antérieurs entre les parties[...]» ${ }^{95}$.

Precisamente, ésta es la misma solución prevista por el Código Civil portugués, de 25 de noviembre de 1966, cuyo artículo 218 -contenido en la sección dedicada al estudio del Acto Jurídico- establece igualmente que el silencio sólo equivaldrá a consentimiento en aquellos casos en los cuales así lo prevean: la ley, el acuerdo de las partes, o los usos:

"O silêncio vale como declaração negocial, quando esse valor lhe seja atribuído por lei, uso ou convençao».

siendo prácticamente reproducido de manera literal este precepto en el Código Civil de Macao -antigua colonia portuguesa ${ }^{96}$, el cual entró en vigor el 1 de noviembre de 1999, y cuyo artículo 210 dispone:

«O silêncio só vale como declaração negocial quando esse valor lhe seja atribuído por lei, uso ou convenção»,

la única diferencia entre uno y otro radica en el hecho de que la legislación de Macao - de fecha posterior- especifica más claramente el carácter excepcional de los tres supuestos en los cuales se admite que el comportamiento silencioso equivalga a consentimiento a través de la introducción del adverbio «só» (solamente, únicamente).

Un paso más en cuanto al alcance del silencio como declaración de voluntad viene representado por la legislación del Estado de Quebec $^{97}$; en concreto, el artículo 1394 de su código civil añade a las tres circunstancias hasta ahora señaladas: la ley, el acuerdo de las partes y los usos, un cuarto hecho al cual se le atribuye también la virtualidad de provocar que el silencio de un sujeto sea interpretado como

${ }^{95}$ Ver supra nota.

96 Puede consultarse: António DA SILVA REGO, A presença de Portugal em Macau, Lisboa, 1946; Rafael AVILA DE AZEVEDO, A influência da cultura portuguesa em Macau, Lisboa, 1984; AA.VV. Macau: city of commerce and culture, Hong Kong, 1987; Kai Cheong FOK, Estudos sobre a instalaçao dos Portugueses em Macau, Lisboa, 1996; Zhao GUOGIANG, $A B C$ de la ley fundamental de la región administrativa especial de Macao, 1999; Moisés SILVA FERNANDES, Sinopse de Macau nas relaçoes luso-chinesas, 1945-1995: cronologia e documentos, Lisboa, 2000.

${ }_{97}$ No es ése el lugar para tratar en detalle la especial situación jurídica de Quebec dentro de Canadá, pudiéndose consultar al respecto: Michael KEATING, Naciones contra el Estado. El nacionalismo de Cataluña, Quebec y Escocia, Barcelona, 1996; Alejandro SAIZ ARNAIZ, Estado Federal y "Estado Particular». La posición constitucional de la provincia de Quebec en la federación canadiense, Madrid, 1997; Alain G. GAGNON, Quebec y el federalismo canadiense, Madrid, 1998; AA.VV., La portée de l'autonomie politique du Québec, Barcelona, 2006. 
asentimiento a un determinado acuerdo o propuesta. Se trata de la existencia, no ya de usos, sino de relaciones comerciales previas entre las partes:

«Le silence ne vaut pas acceptation, à moins qu'il n'en résulte autrement de la volonté des parties, de la loi ou de circonstances particulières, tels les usages ou les relations d'affaires antérieures».

Esta referencia de la legislación de Quebec viene a poner el acento en un aspecto hasta ahora no vislumbrado: es precisamente en el ámbito de las relaciones comerciales donde con mayor frecuencia puede o suele plantearse el problema de si la conducta pasiva de un sujeto al cual le ha sido dirigida, bien una propuesta, o incluso en muchas ocasiones ya le han sido remitidas ciertas mercancías, ha de ser interpretada o no como aceptación de dicha propuesta contractual.

Es desde esta perspectiva como es tratado el problema del silencio en el marco del código civil de la República de Turkmenistán, de 1 de marzo de 1999. En concreto, el apartado $1^{\circ}$ de su artículo 349 viene a sentar el principio de que un comerciante tiene la obligación de responder a aquellas solicitudes de prestar su actividad propia y característica que le sean realizadas por terceras personas en un plazo de tiempo razonable, pues en caso de no responder su silencio será interpretado como aceptación, sucediendo lo mismo si él con carácter previo había entrado ya en relaciones comerciales con dichos sujetos ${ }^{98}$; estableciendo, por su parte, el apartado $2^{\circ}$ una protección adicional para aquel sujeto que haya realizado la citada solicitud de servicios, habiéndole además remitido alguna cantidad de mercancías, pues se establece que en caso de que de modo expreso rechace dicha oferta contractual, estará obligado a evitar cualquier tipo de daño o perjuicio a las mismas.

Ahora bien, junto a los ejemplos hasta ahora analizados que vienen a establecer con un cierto grado de objetividad aquellas circunstancias que legitiman al oferente para interpretar el silencio de la contraparte como aceptación de la propuesta que le ha sido dirigida (la ley, el acuerdo previo de las partes o los usos), nos encontramos con

98 En concreto, dicho artículo dispone: «If an entrepreneur carrying out activity for other persons receives an offer on performance of similar activity from the person with whom he has business connections, he shall be obliged to respond to this offer within a reasonable period of time; his silence shall be considered to be acceptance. Same rule shall apply also in the cases when the entrepreneur receives same kind of offer from the person to whom he applied with requests for the implementation of similar activity». 
otros sistemas legislativos en los cuales el legislador no ha establecido con tanta claridad los supuestos en los cuales la pasividad de una parte equivale a su asentimiento.

A este respecto podemos destacar la solución propuesta por otro código norteamericano de tradición europea -el código civil de Louissiana ${ }^{99}$-, el cual con relación al consentimiento contractual establece con carácter general en su artículo 1927 que la aceptación puede efectuarse tanto de modo verbal, como oral, como por medio del comportamiento e incluso a través de la falta de actividad, esto es, del comportamiento silencioso. Ahora bien, señala que dicha inacción sólo podrá ser entendida como consentimiento cuando así derive de las circunstancias que rodeen a la misma:

«A contract is formed by the consent of the parties established through offer and acceptance.

Unless the law prescribes a certain formality for the intended contract, offer and acceptance may be made orally, in writing, or by action or inaction that under the circumstances is clearly indicative of consent.

Unless otherwise specified in the offer, there need not be conformity between the manner in which the offer is made and the manner in which the acceptance is made».

En cualquier caso, mientras que a la posibilidad de que el inicio de la ejecución de una determinada prestación sea interpretable como consentimiento a la propuesta contractual recibida, el citado

99 Ver: H. P. DART, The Place of the Civil Law in Louisiana, en «Tulane Law Review», vol. 4, 1930, págs. 163-ss.; R. POUND, The Influence of the Civil Law in America, en «Louisiana Law Review», vol. 1, 1938, págs. 1-ss.; H. JOLOWICZ, The Civil Law in Louisiana, en «Tulane Law Review», vol. 29, 1955, págs. 491-ss.; J. H. TUCKER, The Code, Customs, and the Common Law in Louisiana, en "Tulane Law Review», vol. 29, 1955, págs. 739-ss.; R. BATIZA, The Influence of Spanish Law in Louisiana, en «Tulane Law Review», vol. 33, 1958, págs. 29-ss; J. L. BADOUIN, The Influence of the Code Napoleon, en «Tulane Law Review», vol. 33, 1958, págs. 21-ss.; R. BATIZA, The Louisiana Civil Code of 1808: Its actual sources and present relevance, en "Tulane Law Review», vol. 46, 1971, págs. 4-ss.; Shael HERMAN, The Influence of Roman Law upon the Jurisprudence of Antebellum Louisiana, en "Stellenbosch Law Review», 1992, págs. 196-ss.; Shael HERMAN, The Louisiana Civil Code: a European Legacy for the United States, New Orleans, 1993; Shael HERMAH, Der Einfluss des römischen Rechts auf die Rechtswissenschaft Louisianas vor dem amerikanischen Bürgerkrieg, en «Z.S.S.», vol. CXIII, 1996, págs. 293-345; Symon C. SYMEONIDES, Louisiana's Reception and preservation of the Romanist Legal Tradition, en «INDEX», 1996, págs. 515518; Rolf KNÜTEL, Einflüsse des Louissiana Civil Code in Latein-Amerika, en "INDEX», 1997, págs. 117-144; Alfredo MORDECHAI RABELLO, Sulla codificazione in Louissiana, en «INDEX», 1997, págs. 111-116. 
código civil del Estado de Louissiana le dedica los artículos 1939, 1940 y 1941, de cuya lectura se desprende claramente la intención de regular con gran detalle esta cuestión, procurando dejar el mínimo espacio posible a eventuales problemas en el tráfico jurídico ordinario ${ }^{101}$; en cambio, a la aceptación mediante el silencio sólo le dedica el artículo 1942, el cual dispone:

«When, because of special circumstances, the offeree's silence leads the offeror reasonably to believe that a contract has been formed, the offer is deemed accepted",

es decir, este artículo se limita a reiterar la misma solución ya planteada en el precepto que con carácter general analizaba la pro-

101 Así, el legislador de Louissiana dispone, en primer lugar, en su artículo 1939 que para que sea posible entender como aceptado un contrato a través de la ejecución de la prestación debida por parte de aquél a quien le ha sido efectuada la oferta contractual, el oferente debe haber indicado esta cuestión de modo expreso en dicha oferta, debiendo igualmente derivar de los términos de ésta o de los usos habituales que una vez iniciada la ejecución de la prestación debida, ésta se completará: «When an offeror invites an offeree to accept by performance and, according to usage or the nature or the terms of the contract, it is contemplated that the performance will be completed if commenced, a contract is formed when the offeree begins the requested performance».

Pero, además, el artículo 1940 plantea otra hipótesis factible de plantearse en la realidad práctica: ¿qué sucede en el caso de que nos encontremos ante una oferta que según los usos o sus propios términos pueda ser aceptada mediante la ejecución -se entiende que total- de la prestación debida, la cual es iniciada por el intimado: puede ser revocada dicha oferta mientras todavía se está realizando dicha prestación, una vez iniciado su cumplimiento es posible desistir del mismo? La solución por la cual opta el legislador norteamericano es proteger al máximo los intereses del aceptante, al establecer que el oferente no podrá en principio retirar la oferta si ya se ha iniciado la ejecución de la prestación debida, así como tampoco podrá exigir la finalización de la ejecución iniciada: «When, according to usage or the nature of the contract, or its own terms, an offer made to a particular offeree can be accepted only by rendering a completed performance, the offeror cannot revoke the offer, once the offeree has begun to perform, for the reasonable time necessary to complete the performance. The offeree, however, is not bound to complete the performance he has begun. The offeror's duty of performance is conditional on completion or tender of the requested performance».

Ahora bien, el código de Louissiana también contiene en su artículo 1941 otra disposición tendente, en este caso, si no a otorgar algún tipo de ventaja al oferente, al menos a procurarle una cierta seguridad jurídica, al obligar a aquel sujeto que acepte una oferta contractual mediante el inicio de la ejecución de la prestación debida a notificar dicha aceptación al oferente en el menor plazo posible, estableciendo incluso su eventual responsabilidad por los daños que la falta de la misma pudiera producir al oferente: «When commencement of the performance either constitutes acceptance or makes the offer irrevocable, the offeree must give prompt notice of that commencement unless the offeror knows or should know that the offeree has begun to perform. An offeree who fails to give the notice is liable for damages». 
blemática del consentimiento contractual: esto es, el silencio deberá ser interpretado como consentimiento cuando así se derive de special circumstances; pero, ¿cuáles son esas «circunstancias especiales» que pueden conducir al oferente a interpretar que el silencio mantenido por aquél a quien le ha dirigido su propuesta puede ser interpretado como asentimiento a la misma? Sin duda, esta solución legislativa dista mucho de resolver algún problema, sino más bien procede a plantearlos. 